\title{
Retracted: Intravenous Leiomyoma with Extension to the Heart: A Case Report and Review of the Literature
}

\author{
Case Reports in Obstetrics and Gynecology \\ Received 22 July 2014; Accepted 22 July 2014; Published 3 August 2014 \\ Copyright (C) 2014 Case Reports in Obstetrics and Gynecology. This is an open access article distributed under the Creative \\ Commons Attribution License, which permits unrestricted use, distribution, and reproduction in any medium, provided the \\ original work is properly cited.
}

\begin{abstract}
The article titled "Intravenous Leiomyoma with Extension to the Heart: A Case Report and Review of the Literature" [1], published in Case Reports in Obstetrics and Gynecology, has been retracted as it is found to contain a substantial amount of material, without referencing, from the published article titled "Surgical management of intravenous leiomyoma with cardiac extension. Do we need total circulatory arrest?" by S. Senay, U. Kaya, H. Cagil, F. Demirkiran, C. Alhan, The Thoracic and Cardiovascular Surgeon 2007; 55(5): 322-323. DOI: 10.1055/s-2007-964953. Also, the article was submitted for publication by Veysel Sal without the knowledge and approval of the coauthors Umit Kaya and Cem Alhan.
\end{abstract}

\section{References}

[1] F. Demirkiran, V. Sal, K. Umit, C. Alhan, and N. Tokgozoglu, "Intravenous leiomyoma with extension to the heart: a case report and review of the literature," Case Reports in Obstetrics and Gynecology, vol. 2013, Article ID 602407, 3 pages, 2013. 